OPEN ACCESS

Edited by:

Mariana Mondragón-Palomino, University of Regensburg, Germany

Reviewed by: Teemu Heikki Teeri, University of Helsinki, Finland Xiang Gao,

Key Laboratory of Molecular Epigenetics of MOE, Northeast Normal University, Changchun, China

Michal Oren-Shamir, Agricultural Research Organization,

Israel

*Correspondence: Heidi Halbwirth heidrun.halbwirth@tuwien.ac.at

Specialty section This article was submitted to

Plant Biotechnology,

a section of the journal

Frontiers in Plant Science

Received: 11 September 2017 Accepted: 29 January 2018 Published: 28 February 2018

Citation: Haselmair-Gosch C, Miosic S Nitarska D, Roth BL, Walliser B, Paltram R, Lucaciu RC, Eidenberger L, Rattei T, Olbricht $K$ Stich K and Halbwirth H (2018) Great

Cause-Small Effect: Undeclared

Genetically Engineered Orange Petunias Harbor an Inefficient Dihydroflavonol 4-Reductase.

Front. Plant Sci. 9:149. doi: 10.3389/fpls.2018.00149

\section{Great Cause-Small Effect: Undeclared Genetically Engineered Orange Petunias Harbor an Inefficient Dihydroflavonol 4-Reductase}

\author{
Christian Haselmair-Gosch ${ }^{1}$, Silvija Miosic ${ }^{1}$, Daria Nitarska ${ }^{1}$, Barbara L. Roth ${ }^{1}$, \\ Benjamin Walliser ${ }^{1}$, Renate Paltram ${ }^{1}$, Rares C. Lucaciu ${ }^{2}$, Lukas Eidenberger ${ }^{1}$, \\ Thomas Rattei ${ }^{2}$, Klaus Olbricht ${ }^{3}$, Karl Stich ${ }^{1}$ and Heidi Halbwirth ${ }^{1 *}$ \\ ${ }^{1}$ Institute of Chemical, Environmental and Bioscience Engineering, Technische Universität Wien, Vienna, Austria, \\ ${ }^{2}$ Department of Microbiology and Ecosystem Science, University of Vienna, Vienna, Austria, ${ }^{3}$ Thaer-Institute of Agricultural \\ and Horticultural Sciences Humboldt University Berlin, Berlin, Germany
}

A recall campaign for commercial, orange flowering petunia varieties in spring 2017 caused economic losses worldwide. The orange varieties were identified as undeclared genetically engineered (GE)-plants, harboring a maize dihydroflavonol 4-reductase (DFR, $A_{1}$ ), which was used in former scientific transgenic breeding attempts to enable formation of orange pelargonidin derivatives from the precursor dihydrokaempferol (DHK) in petunia. How and when the $A_{1}$ cDNA entered the commercial breeding process is unclear. We provide an in-depth analysis of three orange petunia varieties, released by breeders from three countries, with respect to their transgenic construct, transcriptomes, anthocyanin composition, and flavonoid metabolism at the level of selected enzymes and genes. The two possible sources of the $A_{1} \mathrm{cDNA}$ in the undeclared GE-petunia can be discriminated by PCR. A special version of the $A_{1}$ gene, the $A_{1}$ type 2 allele, is present, which includes, at the $3^{\prime}$-end, an additional 144 bp segment from the non-viral transposable Cin4-1 sequence, which does not add any functional advantage with respect to DFR activity. This unequivocally points at the first scientific GE-petunia from the 1980s as the $A_{1}$ source, which is further underpinned e.g., by the presence of specific restriction sites, parts of the untranslated sequences, and the same arrangement of the building blocks of the transformation plasmid used. Surprisingly, however, the GE-petunia cannot be distinguished from native red and blue varieties by their ability to convert DHK in common in vitro enzyme assays, as DHK is an inadequate substrate for both the petunia and maize DFR. Recombinant maize DFR underpins the low DHK acceptance, and, thus, the strikingly limited suitability of the $A_{1}$ protein for a transgenic approach for breeding pelargonidin-based flower color. The effect of single amino acid mutations on the substrate specificity of DFRs is demonstrated. Expression of the $A_{1}$ gene is generally lower than the petunia $D F R$ expression despite being under the control 
of the strong, constitutive p35S promoter. We show that a rare constellation in flavonoid metabolism - absence or strongly reduced activity of both flavonol synthase and B-ring hydroxylating enzymes - allows pelargonidin formation in the presence of DFRs with poor DHK acceptance.

Keywords: Petunia $\times$ hybrida, Zea mays, dihydroflavonol 4-reductase, $A_{1}$ type 2 allele, anthocyanin, pelargonidin, orange flower color, transgenic plant

\section{INTRODUCTION}

The color of anthocyanin pigments is determined by their B-ring hydroxylation pattern (Figure 1), ranging from orange to bright red (one hydroxy group), dark red to magenta (two hydroxy groups), and violet to blue (three hydroxy groups; Halbwirth, 2010). This basically depends on two factors, which have both been exploited by biotechnological methods to influence flower color (Meyer et al., 1986; Tanaka et al., 2009, 2010): the presence of enzymes introducing hydroxy groups vicinal to that in position $4^{\prime}$ [flavonoid $3^{\prime}$-hydroxylase $\left(\mathrm{F}^{\prime} \mathrm{H}\right)$ and flavonoid $3^{\prime} 5^{\prime}$-hydroxylase $\left.\left(\mathrm{F}^{\prime} 5^{\prime} \mathrm{H}\right)\right]$, and the substrate specificity of DFR (Winkel-Shirley, 2001).

Important ornamental plants such as petunia, African violet and cyclamen do not naturally produce orange/bright-red flowers (Johnson et al., 1999) because they lack the ability to synthesize pelargonidin-type anthocyanin pigments. This is based on the presence of a substrate specific dihydroflavonol 4reductase (DFR) enzyme, which does not accept the essential precursor, dihydrokaempferol (DHK), as a substrate.

DFR is an oxidoreductase (EC 1.1.1.219) that catalyzes the NADPH dependent stereospecific reduction of the keto group of $(+)-(2 R, 3 R)$-dihydroflavonols in position 4 to the respective (2R,3S,4S)-flavan-2,3-trans-3,4-cis-diols (leucoanthocyanidins), as well as the reverse reaction in the presence of $\mathrm{NADP}^{+}$ (Halbwirth et al., 2006; Petit et al., 2007). DFR is the first of the so-called "late" enzymes of the flavonoid pathway which shows a major impact on the formation of anthocyanin pigments, flavan 3 -ols and flavonols. DFR provides the immediate precursors for the formation of anthocyanidins and flavan 3-ols, the building blocks of condensed tannins. On the formation of flavonols, DFR has an indirect effect. DFR competes with flavonol synthase (FLS), which opens a side branch of the anthocyanin pathway, for common substrates (Winkel-Shirley, 2001; Figure 1). Several DFRs can convert dihydroflavonols irrespective of their hydroxylation pattern, but petunia possesses a DFR that does not convert DHK into leucopelargonidin. In the 1980s and 1990s genetically engineered (GE)-petunias with orange flowers were created by introducing either a maize DFR encoded by the $A_{1}$ gene (Meyer et al., 1986; Elomaa et al., 1995) or a gerbera DFR (Elomaa et al., 1995).

The petunia belongs to the predominant balcony and bedding plants worldwide. A few years ago petunia varieties, showing a novel orange flower color, started to appear on the market and were swiftly adopted in private and public flower arrangements, in Europe and the US. Recently, the vast majority of them turned out to be genetically modified, after PCR-screening for the
35S-promoter and the $A_{1}$ gene (Bashandy and Teeri, 2017; David, 2017; Servick, 2017).

We selected three varieties, released by breeders from three countries, for an-in-depth investigation of the presence and nature of a transgenic construct and its impact on the flavonoid metabolism. We show that they all carry the same construct, and that this can be traced back to the first GE-petunia (Meyer et al., 1986) with near absolute certainty. But surprisingly, the orange petunias were not characterized by a drastically changed DFR substrate specificity compared to common red and blue petunia flowers, as would have been expected. We aimed on elucidating this paradox and demonstrate that the orange petunia owe their color primarily to a rare biochemical background. We underpin this by flavonoid analyses together with enzyme assays and expression and transcriptome studies.

\section{MATERIALS AND METHODS}

\section{Material}

Flowers (stage 1: buds of $0.6-3 \mathrm{~cm}$ length, stage 2: buds of 3$5 \mathrm{~cm}$ length, stage 3: open flowers) of cv. Salmon Ray (Danziger, Moshav Mishmar Hashiva, Israel), cv. Viva Orange (Florensis, Ambacht, The Netherlands), and cv. Electric Orange (Selecta One, Stuttgart, Germany) were harvested in the summers 20152017. Non-transgenic control plants of Petunia $\times$ hybrida cv. BabyDoll were obtained from Selecta One, cvs. Corso Rot, Corso Blau and Blackberry were purchased from Austrosaat (Vienna, Austria). The plant material was harvested from balcony pots or garden beddings, shock-frozen and kept at $-80^{\circ} \mathrm{C}$ until analysis. Images of the petunia varieties are found in Figures 1, 2 and Supplementary Figure S3.

Reference compounds (cyanidin, delphinidin, malvidin, pelargonidin, peonidin, petunidin, dihydromyricetin, dihydroquercetin, kaempferol, myricetin, and quercetin) were purchased from Extrasynthese (Genay, France), dihydrokaempferol from Sigma Aldrich (Vienna, Austria). Radiolabeled substrates were synthesized as previously described (Halbwirth et al., 2006).

\section{HPLC Analysis}

For analyzing the flavonoid class/anthocyanidin type composition in the petals, sugar moieties were removed by acidic or enzymatic hydrolysis. $1 \mathrm{~g}$ plant material was extracted with $1 \mathrm{ml} 2 \mathrm{M}$ hydrochloric acid in methanol. For anthocyanin analysis, $40 \mu \mathrm{l}$ of the supernatant after centrifugation were incubated with $160 \mu \mathrm{l} 4 \mathrm{~N} \mathrm{HCl}$ for $60 \mathrm{~min}$ at $95^{\circ} \mathrm{C}$. For analysis of other flavonoids, $20 \mu \mathrm{l}$ of the supernatant were subjected to enzymatic hydrolysis by $10 \mathrm{U}$ Naringinase (Sigma-Aldrich, 


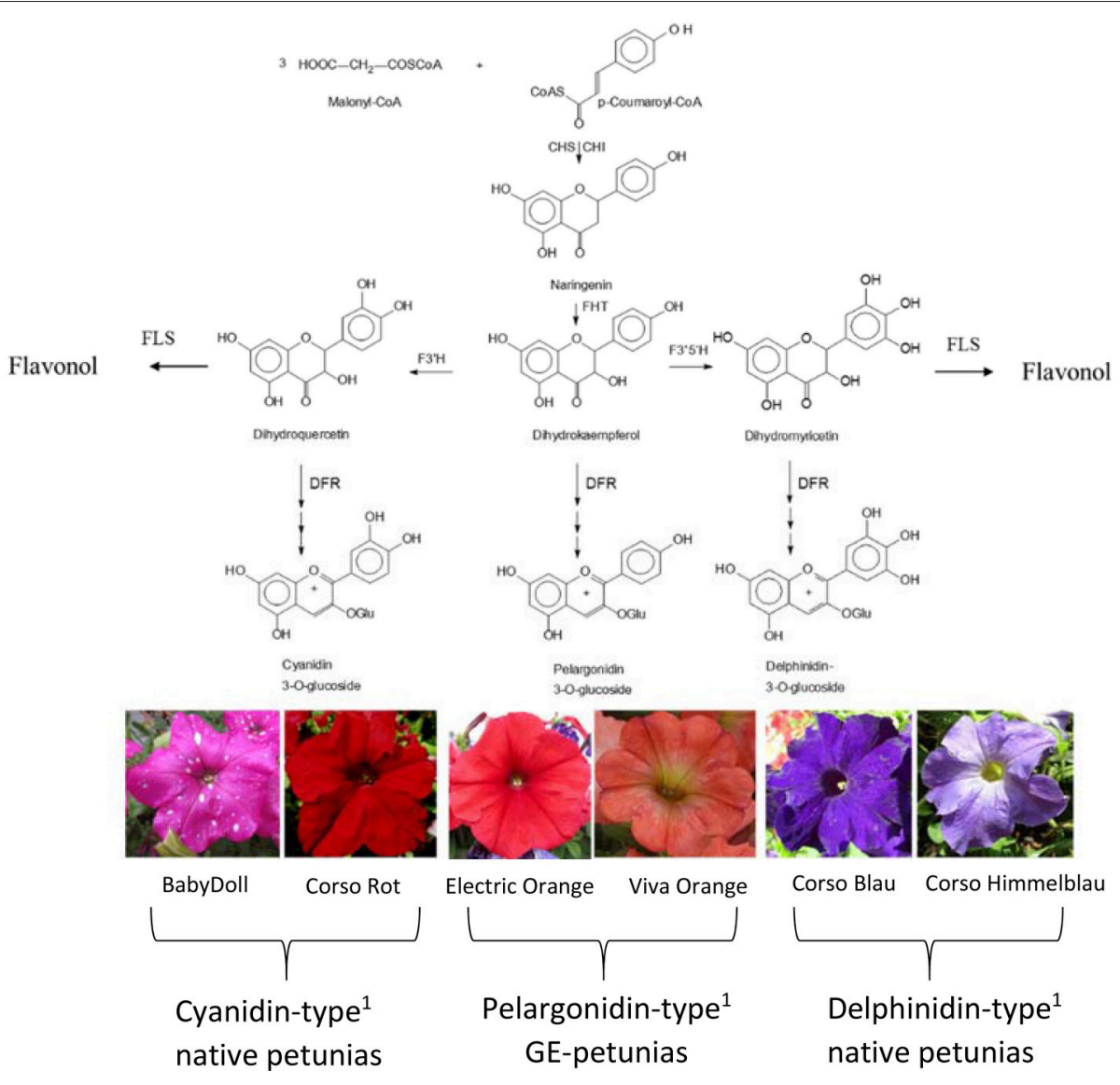

FIGURE 1 | Simplified flavonoid pathway demonstrating the influence of the B-ring hydroxylation pattern on the establishment of petunia flower color. ${ }^{1}$ Petals contain prevalently the respective anthocyanidin type. CHS, Chalcone synthase; $\mathrm{CH}$, chalcone isomerase; DFR, dihydroflavonol 4-reductase; FHT, flavanone 3-hydroxylase; $\mathrm{F}^{\prime} \mathrm{H}$, flavonoid $3^{\prime}$-hydroxylase; F3'5'H, flavonoid $3^{\prime}, 5^{\prime}$-hydroxylase; FLS, flavonol synthase.

Vienna, Austria) and hydrolysed for $20 \mathrm{~min}$ at $40^{\circ} \mathrm{C}$ in $0.1 \mathrm{M}$ McIlvaine buffer $\mathrm{pH} 4$. After hydrolysis, solid compounds were removed by centrifugation, and $4 \mu \mathrm{l}$ of the supernatants were injected after filtration by $0.2 \mu \mathrm{m}$ syringe filters.

HPLC analysis was performed on a Thermo Scientific Dionex UltiMate ${ }^{\circledR} 3000$ RSLC System with DAD-3000RS Photodiode Array Detector (Thermo Scientific, Germany) using an Acclaim $^{\mathrm{TM}}$ column RSLC $120 \mathrm{C} 18,2.2 \mu \mathrm{m}, 120 \AA$, $2.1 \times$ $150 \mathrm{~mm}$ (Dionex Bonded Silica Products: No. 071399) operated at $25^{\circ} \mathrm{C}$. For analysis of anthocyanidins, elution solvents were (A) $10 \%$ formic acid and (B) $10 \%$ formic acid $/ 22.5 \%$ acetonitrile/22.5\% methanol in water ( $\mathrm{v} / \mathrm{v})$ using a slightly modified method from Thermo Scientific Application note 281 (gradient: -10 to 0 min $9 \%$ B, 0-30 min 9-90\% B, 30-40 min 90\% $\mathrm{B}$; flow rate $0.2 \mathrm{ml} / \mathrm{min}$ ). For analysis of other flavonoids, elution solvents were (A) $0.1 \%$ formic acid and (B) $0.1 \%$ formic acid in acetonitrile (gradient: -3 to 0 min $20 \%$ B, $0-15$ min $20-53 \%$ B, $15-20$ min $53-95 \%$ B; $20-30$ min $95 \%$ B, $31-35$ min $20 \%$ B; flow rate $0.2 \mathrm{ml} / \mathrm{min}$ ). Anthocyanidins were detected at $520 \mathrm{~nm}$, other flavonoids at $290 \mathrm{~nm}$. All compounds were identified by retention times and comparison of their UV-VIS spectra from 190 to $800 \mathrm{~nm}$. The concentrations were calculated from the peak areas of samples and standard lines obtained with the respective reference compounds. Methylated anthocyanidins are not listed separately (Table 1), but were included according to their number of hydroxy groups in the delphinidin type (petunidin, malvidin) or cyandin type (peonidin) anthocyanidins. Relative contents of anthocyanidin types (\% Pg/Cy/Dp based pigments was calculated from the $[\mu \mathrm{g} / \mathrm{g}]$ values in Table 1 . Flavonoid class distribution (\% anthocyandins/flavonols/dihydroflavonols) were calculated from the $[\mu \mathrm{g} / \mathrm{g}]$ values in Table 1 in relation to a mathematical total amount of flavonoids resulting from the three types.

\section{PCR, qPCR}

Genomic DNA was obtained according to Lipp et al. (1999). mRNA was extracted with the $\mu$ MACS mRNA isolation Kit (Miltenyi Biotec, Germany) and cDNA was synthesized as described (Thill et al., 2012). PCR and qPCR primers are listed in Supplementary Table S1. PCR was performed with the GoTaq DNA polymerase (Promega, Germany). Quantitative gene expression (at least in biological triplicates with three technical replications each) of DFR, $A_{1}, F 3^{\prime} H$, and FLS in comparison to the actin reference gene (Mallona et al., 2010) 


\section{Variety \\ Flavonoid content \\ $A_{1}: P h D F R$ gene expression ratio \\ $\%$ Pelargonidin (\% rel)}
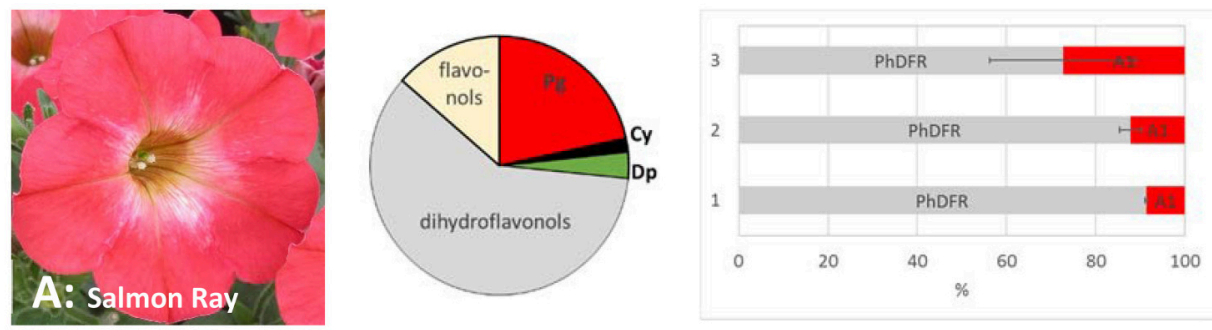

$81 \pm 1.4$

$89 \pm 1.8$

$80 \pm 1.9$
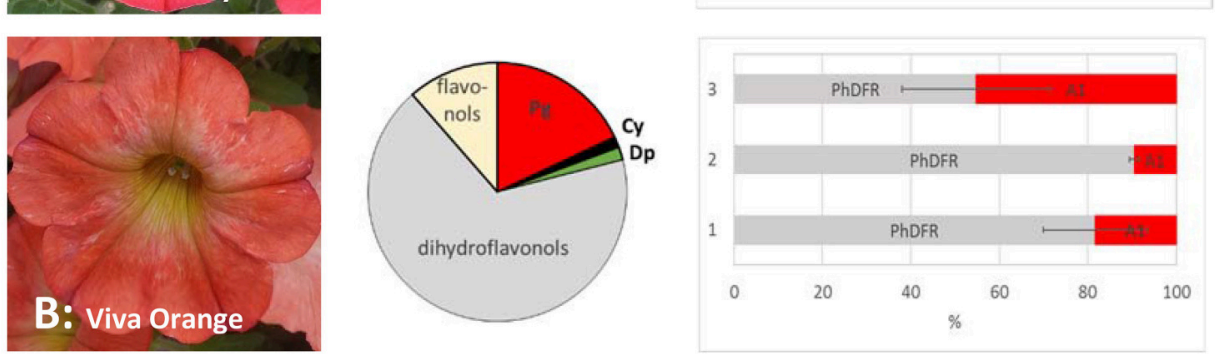

$86 \pm 1.7$

$92 \pm 2.3$

$91 \pm 2.9$
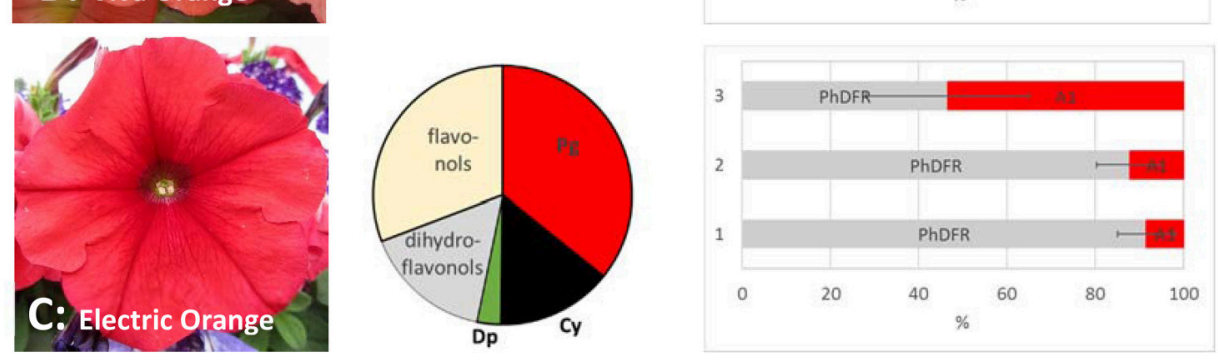

$66 \pm 8.1$

$69 \pm 6.8$

$64 \pm 12.5$

FIGURE 2 | Flavonoid content, $A_{1}$ :PhDFR gene expression ratio and relative pelargonidin content of flowers from Petunia $\times$ hybrida cv. Salmon Ray (A), cv. Viva Orange (B), and cv. Electric Orange (C). Pie chart (bright red: pelargonidin (Pg), black: cyanidin (Cy), green: delphinidin (Dp), gray: dihydroflavonols, yellow: flavonols) of flavonoid contents (for absolute values see Table 1). Bar chart with the ratio of A1:PhDFR gene expression in \% rel for each developmental stage (1: buds of $0.6-3 \mathrm{~cm}$ length, 2: buds of 3-5 cm length, 3: open flowers). Standard deviation (error bars) in $A_{1}$ and PhDFR gene expression ratios for each developmental stage are shown. Portions of pelargonidin based pigments of the anthocyanidins in total are given in \% pelargonidin in the three stages of each cultivar.

were analyzed with a StepOnePlus system (Applied Biosystems, CA, USA) and the Luna ${ }^{\circledR}$ Universal qPCR Master Mix (New England Biolabs, Ipswich, UK). The relative expression ratio was calculated according to Pfaffl (2001). The efficiency of the PCR-reaction was determined on the basis of standard curves which were obtained by applying different DNA concentrations and calculated from the given slopes in the StepOne software according to equation $E=10^{(-1 / \text { slope })}$ (Pfaffl, 2001). All qPCR primers had an efficiency between 90 and 110\% (for amplification efficiencies see Supplementary Table S1). The product specificity was confirmed by melting curve analysis and gel electrophoresis. Sequencing of PCR products was done by a commercial supplier (Microsynth, Vienna, Austria).

\section{Transcriptome Analysis}

Plant material was harvested in summer 2016 and shock-frozen with liquid nitrogen. Preparation of rRNA, depleted RNA, random-primed cDNA and Illumina PE sequencing (50 million $150 \mathrm{bp}$, paired-end reads) was performed by a commercial supplier (vertis AG, Freising, Germany) on an Illumina NextSeq 500 system using $2 \times 150 \mathrm{bp}$ read length.
The random tagged prime RNA-seq data was first analyzed with the common NGS (next generation sequencing) analysis tools: First, the entire rRNA database provided by the tool was analyzed with sortmerna (v 2.1; Kopylova et al., 2012). From the remaining reads, the low-quality reads (below 20 quality score) were trimmed using trimmomatic (v 0.36) (Bolger et al., 2014) and the parameters TRAILING:20 AVGQUAL:20 SLIDINGWINDOW:5:20 MINLEN:75. Reads were mapped against the available Petunia axillaris genome (Bombarely et al., 2016), in which we incorporated the sequence of $A_{1}$ (NCBI CAA28734) to allow a quantification of the transgene expression. FPKM (Fragments Per Kilobase of transcript per Million mapped reads) were obtained using the method for quantification of RNA expression RSEM (v 1.3.0) (Li and Dewey, 2011).

\section{Recombinant DFR}

The DFR cDNA clone of $P$. hybrida was synthesized by GeneCust Europe (Dudelange, Luxembourg) based on the sequence available in the database (NCBI X15537). The $A_{1}$ cDNA clone (NCBI CAA28734) from maize was provided by Udo Wienand 
TABLE 1 | Flavonoid composition ([ $\mu \mathrm{g} / \mathrm{g} \mathrm{FW]}$ and \% rel) of methanolic extracts of three orange flowering petunias after acidic and enzymatic hydrolysis in comparison to the non-GE cultivars Corso Rot (red), Corso Blau (blue) and BabyDoll (pink with white dots).

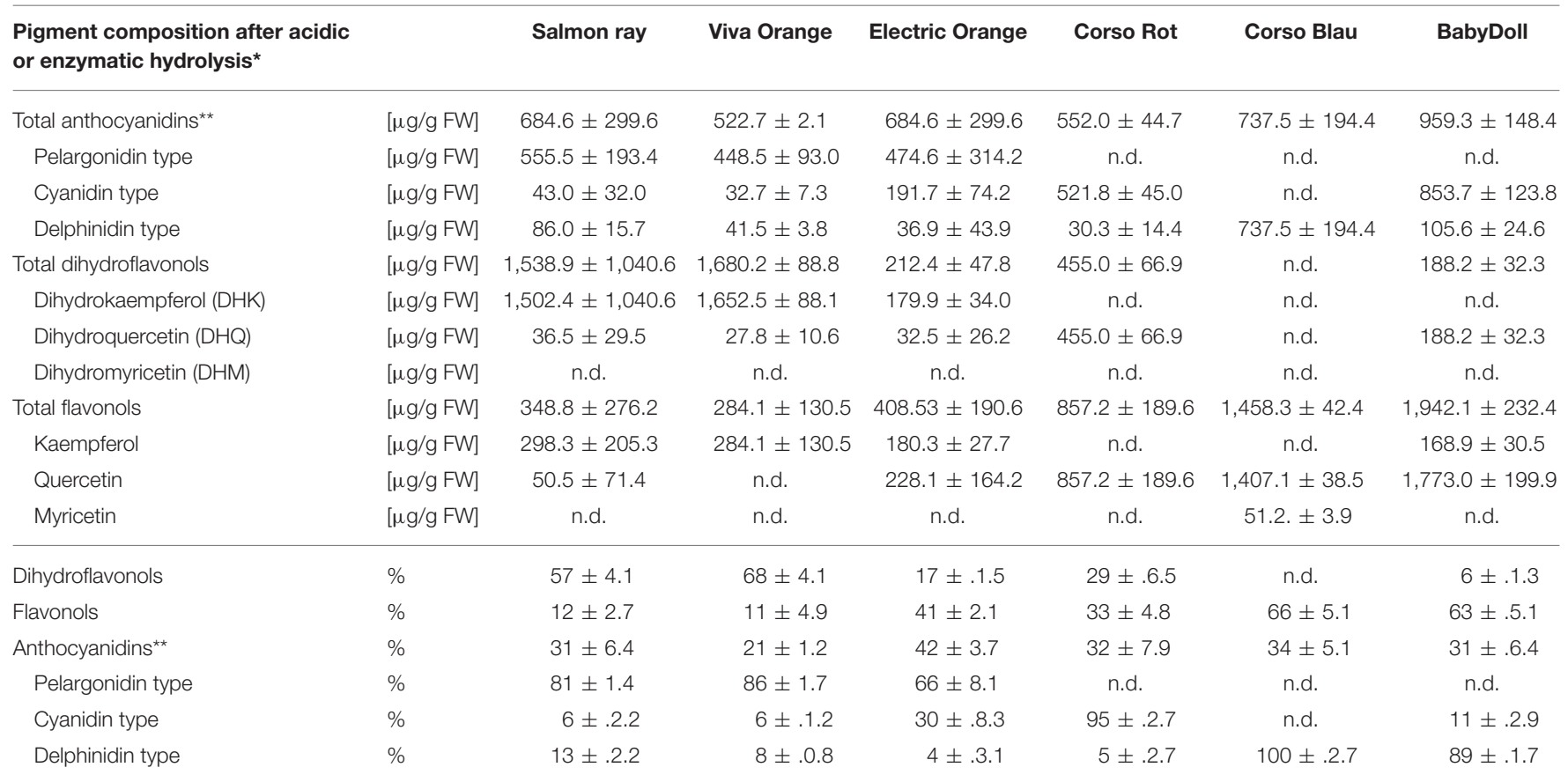

Pictures of the cultivars are incorporated in Figure 1.

${ }^{*}$ Average values and standard deviations were calculated from at least three biological replications collected at different sites. Large standard deviations of absolute values [ $\mu \mathrm{g} / \mathrm{g}$ fresh weight (FW)] partially result from the strong variation of flavonoid contents with external factors such as lighting conditions. But even from the same plants, flowers with divergent color intensity could be collected (details not shown). Despite this, the relative distribution [\%] between the flavonoid classes (anthocyanins, dihydroflavonols, and flavonols) and within anthocyanidins (pelargonidin-, cyanidin-, delphinidin based pigments) was quite stable.

${ }^{\star}$ Methylated anthocyanidins are not shown separately, but were included according to their number of hydroxy groups in the delphinidin type (petunidin, malvidin) or cyandin type (peonidin) anthocyanidins.

n.d. not detected.

(University of Hamburg, Germany). The cDNA clones were used for subcloning into the bacterial expression vector pGEX-6P-1 (GE Healthcare, Munich, Germany) for overexpression of the DFRs as GST-fusion proteins, as described previously (Gosch et al., 2014), using primers $A_{1}$ DFR-FL, $A_{1}$ DFR-FS, $A_{1}$ DFR-RL, $A_{1}$ DFR-RS, and PhDFR-FL, PhDFR-FS, PhDFR-RL, PhDFR-RS, respectively (Supplementary Table S2).

\section{Enzyme Assays}

DFR assays with recombinant enzyme or preparations from flowers were performed as described previously (Gosch et al., 2014).

\section{Site Directed Mutagenesis}

Mutants were generated by use of the Q5 ${ }^{\circledR}$ Site-Directed Mutagenesis Kit (NewEngland Biolabs, Vienna, Austria). Primers were designed using the NEBase Changer ${ }^{\mathrm{TM}}$ provided at http://nebasechanger.neb.com. The sequences are given in Supplementary Table S2. The integrity of the constructs was confirmed by commercial sequencing (Microsynth, Vienna, Austria).

\section{Statistical Analysis}

The statistical analysis of the qPCR data was performed using RStudio v 1.0.136 and R v 3.3.3 with the package "agricolae"
(Ihaka and Gentleman, 1996; De Mendiburu, 2017). ShapiroWilk test was used for testing on normality (Razali and Wah, 2011). A Wilcoxon rank sum test was used for not normal distributed data and a paired $t$-test was used for normal distributed data, respectively. The correlation between pelargonidin content and the expression ratio of $P h D F R$ was calculated using the Pearson correlation coefficient (Duncan, 1955). Group-wise comparison of gene expression between different developmental stages and varieties was calculated utilizing Duncan's new multiple range test (MRT) (Duncan, 1955). For all statistical significance tests, the significance level was set to $0.05(5 \%)$.

\section{RESULTS}

\section{Pigment Composition}

We analyzed the pigment composition of three commercially available orange varieties. In all three, pelargonidin based pigments were the prevalent anthocyanins (pie chart in Figure 2, Table 1). Whereas cv. Salmon Ray and cv. Viva Orange contained more than $80 \%$ pelargonidin based pigments and only small amounts of cyanidin and delphinidin derivatives, cv. Electric Orange showed a relatively high content of cyanidin based pigments (30\%), traces of delphinidin based pigments and 66\% 
pelargonidin based pigments. The anthocyanin pattern was relatively stable during flower development and varied only to a minor extent between buds of different size and fully developed flowers (Figure 2 right). Common red, pink, or blue petunia varieties, which were analyzed as controls, accumulated cyanidin or delphinidin based pigments, depending on the color, but no pelargonidin based pigments could be detected (Table 1).

Besides anthocyanins, dihydroflavonols and flavonols were present in the petals (Figure 2, Table 1). In the orange cultivars Salmon Ray and Viva Orange, dihydroflavonols were the prevalent flavonoid class, with more than $55 \%$ of the total flavonoids, whereas relatively small amounts of flavonols (below 15\%) could be found (Table 1, pie charts in Figure 2). As with the anthocyanins, cv. Electric Orange showed a somewhat different composition, with $41 \%$ flavonols and 17\% dihydroflavonols. In the red cv. Corso Rot, concentrations of anthocyanins, dihydroflavonols and flavonols were almost equal, whereas the blue and pink cultivars contained more than 60\% flavonols and no (cv. Corso Blau) or only traces of (cv. BabyDoll) dihydroflavonols (Table 1).

\section{Evidence for a Genetic Modification Event and Identification of the $A_{1}$ Source}

We screened the varieties by PCR for sequences that would indicate the presence of a biotechnological construct. With specific primers for $A_{1}$, nptII and the $35 S$ promoter, PCR fragments could be amplified from genomic DNA of all three varieties (Figure 3), thereby confirming a genetic modification event. To illuminate the origin of the $A_{1}$ source, we analyzed the transgene present in the three orange varieties. Two $A_{1}$ constructs previously used to create orange GE-lines (Meyer et al., 1986; Elomaa et al., 1995) for scientific purposes are the most probable sources. Discrimination by PCR between these is possible (Table in Figure 4), based on the direction of the $A_{1}$ gene, which was either sense (Meyer et al., 1986) or antisense (Elomaa et al., 1995) to the nptII gene. All three orange petunia varieties showed an approximately $2.3 \mathrm{~kb}$ amplicon when PCR with genomic DNA as template and $A_{1}$ specific forward and $n p t I I$ specific reverse primers was performed (Figure 4), as expected only for the construct of Meyer et al. (1986). We furthermore sequenced a $3.3 \mathrm{~kb}$ PCR product obtained from genomic DNA of the three

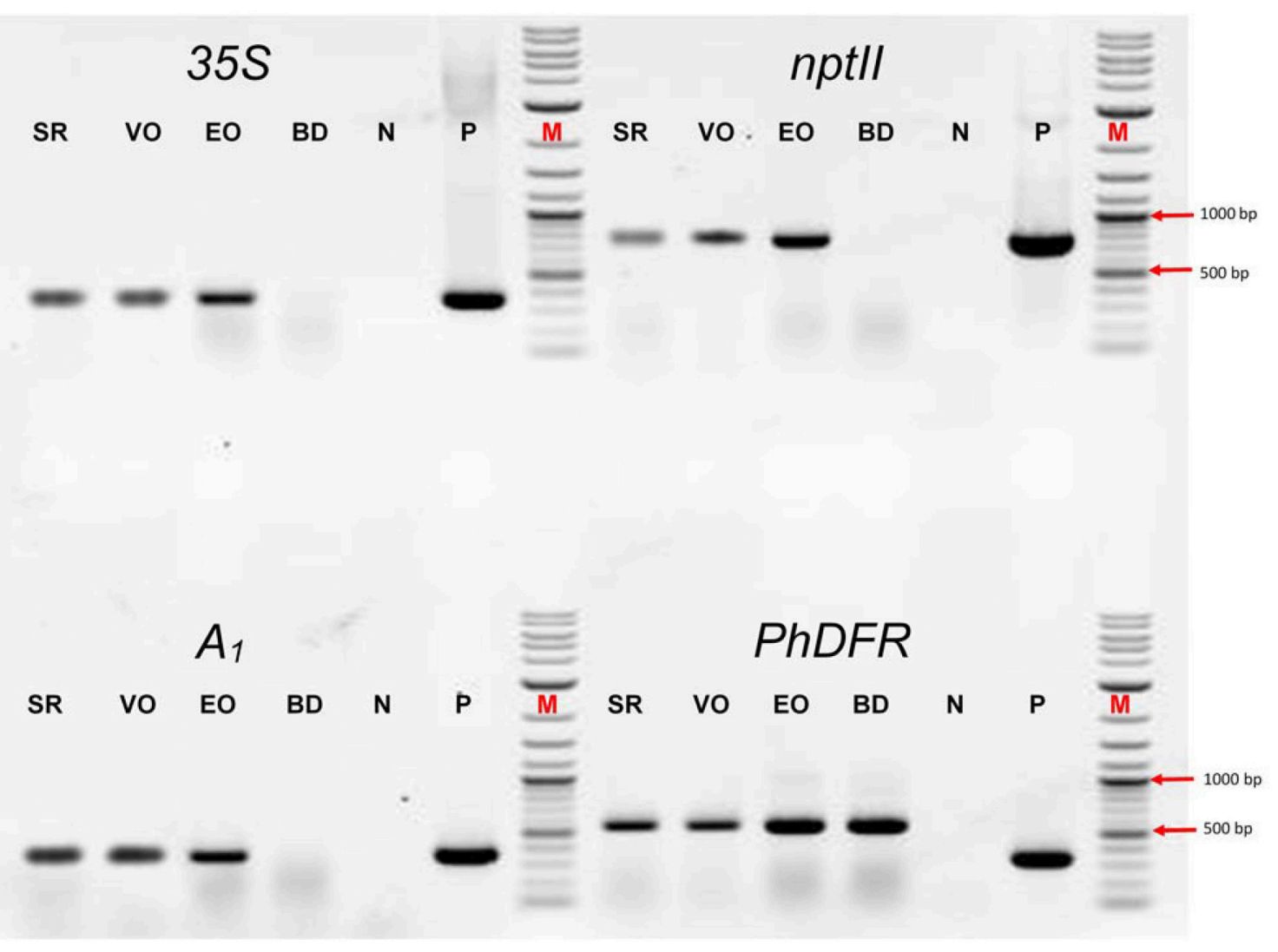

FIGURE 3 | PCR evaluation of genomic DNA of the three orange cultivars Salmon Ray (SR), Viva Orange (VO), and Electric Orange (EO) and the pink-white cultivar BabyDoll (BD) for the presence of specific DNA sequences. Water was used as negative control (N), and plasmids harboring the genes of interest as positive control (P) instead of genomic DNA. M: DNA marker 2-Log DNA Ladder; 1,000 and 500 bp fragments are marked with red arrows. 35S: partial promoter sequence of the 35S Cauliflower mosaic virus gene; nptll: partial coding sequence of the $n p t / l$ selectable marker gene; $A_{1}$ : partial coding sequence of the $A_{1}$ gene; PhDFR: partial coding sequence of the DFR of Petunia $\times$ hybrida. Primer sequences are provided in Supplementary Table S1. For genomic DNA, fragments of 365 bp (35S), 779 bp (nptII), $346 \mathrm{bp}\left(A_{1}\right)$, and $565 \mathrm{bp}(P h D F R)$ are expected. For 35S, nptll and $A_{1}$, expected fragment sizes are identical for control plasmid. For PhDFR, a fragment of 337 bp for control plasmid DNA (cDNA clone) instead of $565 \mathrm{bp}$ (genomic DNA) is expected. 


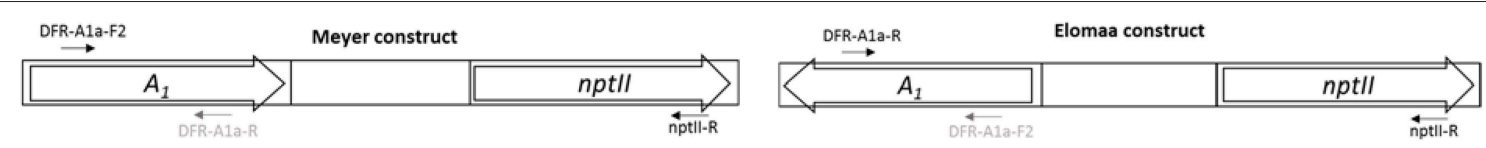

\begin{tabular}{|l|l|l|c|c|c|}
\hline & Primer 1 & Primer 2 & \multicolumn{2}{|c|}{$\begin{array}{c}\text { Amplicon expected for construct of } \\
\text { Meyer }\end{array}$} & $\begin{array}{c}\text { Amplicon obtained with cDNA from } \\
\text { Elomaa }\end{array}$ \\
\hline A & DFR-A1a-F2 & nptll-R & yes (2357 bp) & no & yes \\
\hline B & DFR-A1a-R & nptll-R & no & yes & no \\
\hline
\end{tabular}

A (primer DFR-A1a-F2 + nptll-R)

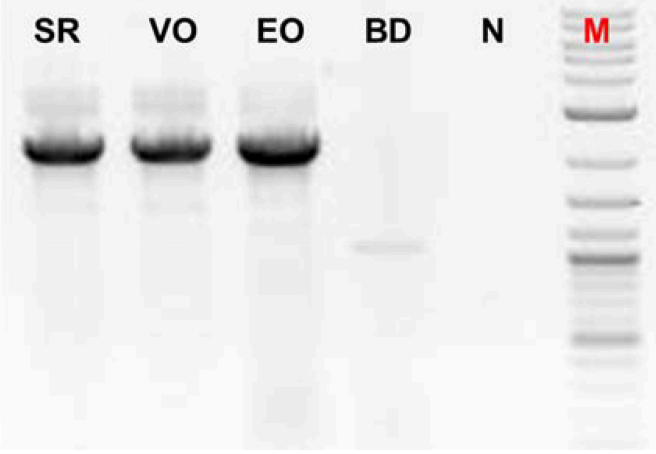

B (primer DFR-A1a-R + nptll-R)

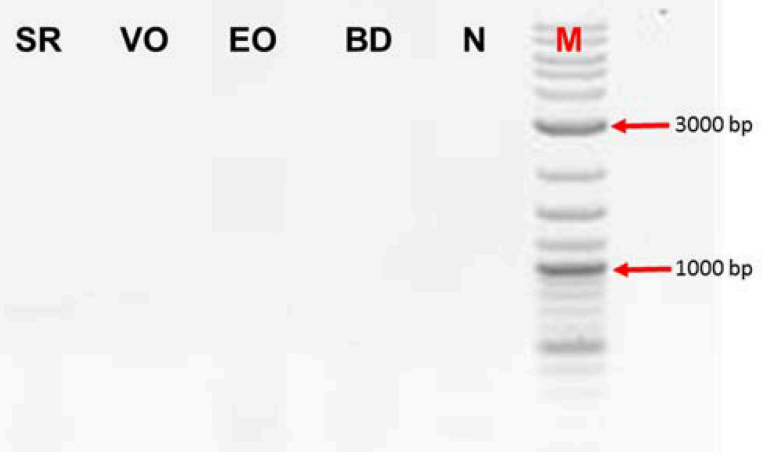

FIGURE 4 | PCR discrimination between the transformation plasmids of Meyer et al. (A1 and npt/l cloned in the sense orientation) and Elomaa et al. (A1 and $n p t / l$ cloned in the antisense direction). PCRs were performed with primer combinations (A) (primer DFR-A1a-F2 + nptll-R) and (B) (primer DFR-A1a-R + nptII-R) with genomic DNA of cvs. Salmon Ray (SR), Viva Orange (VO), Electric Orange (EO), and BabyDoll (BD). N, negative control in which genomic DNA is replaced by water; M, DNA marker 2-Log DNA Ladder; 3,000 and 1,000 bp fragments are marked with red arrows.

orange lines as templates using a $35 S$ promoter specific forward and an OCS terminator specific reverse primer.

All three amplicons showed identical sequences (Supplementary Figure S1) at the nucleotide level (NCBI MF521566). This included a partial sequence of the $35 S$ promoter $(217 \mathrm{bp})$, followed by the restriction sites of $\mathrm{XbaI}$ and EcoRI, a $5^{\prime}$ untranslated region (UTR) of the $A_{1}$ cDNA clone of maize, the 1,074 bp full size $A_{1}$ cDNA clone, and an adjacent $3^{\prime}$ UTR with a 144 bp insertion consisting of the partial Cin4-1 transposable element with a polyA stretch as present in the type 2 allele of $A_{1}$ described by Schwarz-Sommer et al. (1987a,b). After the polyA stretch, we identified an EcoRI and $X b a I$ restriction site, a 226 bp t35S terminator flanked by an EcoRI restriction site, and a selection gene cassette including the pNOS promoter, $n p t I I$ cDNA clone and tOCS terminator (1,402 bp fragment with only partial tOCS).

\section{DFR Substrate Specificity}

Protein preparations obtained from the three orange petunia varieties were, surprisingly, not able to convert DHK under in vitro assay conditions, although they showed DFR activity with dihydromyricetin (DHM) as a substrate (Table 2). DHK conversion with enzyme preparation of the orange petunia petals could be observed neither in buds nor in petals. DHQ was not accepted either, with exception of the enzyme preparations from cv. Electric Orange, which converted DHQ to some extent, although at dramatically lower level than DHM (Table 2). Common blue and red petunias, which were used as controls, showed dihydroflavonol conversion levels that were almost comparable to those of the GE-petunia. High conversion rates were obtained with DHM as substrate, whereas DHK was not converted (Table 2). Conversion of DHQ was much lower than with DHM and lower than those observed with preparations from cv. Electric Orange. To exclude a false negative result, the integrity of DHK was confirmed with enzyme preparations from strawberry (Table 2) which possess a DFR showing high DHK substrate specificity (Miosic et al., 2014). Thus, the orange petunias showed the same lack of DHK acceptance under common DFR assay conditions as the blue and red flowering non-GE controls.

To shed further light on the substrate specificity of the maize DFR encoded by $A_{1}$, we heterologously expressed an $A_{1}$ cDNA clone as GST-fusion protein in E. coli. After removal of the GSTtag, the purified recombinant $A_{1}$ protein showed high substrate specificity, converting DHQ and DHM to a comparable extent, but no conversion of DHK could be observed during time spans sufficient to exhaust DHQ and DHM (Table 2). Even when incubation times with DHK were extended over night or up to $24 \mathrm{~h}$ at $4^{\circ} \mathrm{C}$, no conversion of DHK to leucopelargonidin could be observed in vitro. Kinetic data indicate a comparable substrate specificity for DHM $\left(K_{m} 3.1 \mu \mathrm{M}, \mathrm{V}_{\max } 1.0 \times 10^{-3}\right.$ $\left.\mu \mathrm{M} / \mathrm{s} ; k_{\text {cat }} 0.87 \mathrm{~s}^{-1} ; k_{\text {cat }} / K_{m} 0.28 \mathrm{~s}^{-1} \mu \mathrm{M}^{-1}\right)$ and DHQ $\left(K_{m}\right.$ 
TABLE 2 | Specific DFR activity with DHK, DHQ, and DHM as substrate using enzyme preparations from petals of petunia cultivars and with recombinant DFR from maize and petunia.

\begin{tabular}{|c|c|c|c|c|}
\hline \multirow[b]{2}{*}{ Enzyme source } & \multirow[b]{2}{*}{$\begin{array}{l}A_{1} \\
\text { present }\end{array}$} & \multicolumn{3}{|c|}{$\begin{array}{l}\text { Specific activity [nmol/g protein] } \\
\text { measured with substrate }\end{array}$} \\
\hline & & DHK & DHQ & DHM \\
\hline Salmon Ray buds/open flowers & Yes & $-/-^{\star}$ & $-/-$ & $1.96 / 1.94$ \\
\hline $\begin{array}{l}\text { Electric Orange buds/open } \\
\text { flowers }\end{array}$ & Yes & $-/-^{\star}$ & $0.13 / 0.12$ & $1.96 / 1.96$ \\
\hline Viva Orange buds/open flowers & Yes & $-/-^{\star}$ & $-1-$ & $1.96 / 1.96$ \\
\hline BabyDoll & No & $-1-^{\star}$ & $-1-$ & $1.96 / 1.93$ \\
\hline Corso Rot & No & $-1-^{\star}$ & $0.01 /-$ & $1.96 / 1.94$ \\
\hline Corso Blau & No & $-1-^{\star}$ & $0.03 /-$ & $1.96 / 1.96$ \\
\hline Control reaction (strawberry) & No & 1.96 & 0.25 & 0 \\
\hline recombinant $A_{1}$ protein & & - & 0.33 & 0.55 \\
\hline $\begin{array}{l}\text { Recombinant wild type PhDFR } \\
(137 \mathrm{~L}, 138 \mathrm{D})^{\star \star}\end{array}$ & & - & - & 1.47 \\
\hline $\begin{array}{l}\text { Recombinant PhDFR mutant } \\
(137 \mathrm{~V}, 138 \mathrm{D})^{\star \star}\end{array}$ & & - & - & 1.52 \\
\hline $\begin{array}{l}\text { Recombinant PhDFR mutant } \\
(137 \mathrm{~V}, 138 \mathrm{~N})^{\star \star}\end{array}$ & & & 1.41 & 1.14 \\
\hline $\begin{array}{l}\text { Recombinant PhDFR mutant } \\
(137 \mathrm{~L}, 138 \mathrm{~N})^{\star \star}\end{array}$ & & - & 1.48 & 1.48 \\
\hline
\end{tabular}

Enzyme preparations from strawberry fruits were used as control to demonstrate integrity of the DHK and DHQ substrates.

${ }^{*} D H K$ conversion was not observed even if incubation time was extended to $24 \mathrm{~h}$ at $4{ }^{\circ} \mathrm{C}$; ${ }^{* \star}$ Numbering according to the deduced amino acid sequence of $A_{1}$ as shown in Supplementary Figure S2; -: below detection level.

$2.9 \mu \mathrm{M}, \mathrm{V}_{\max } 1.25 \times 10^{-3} \mu \mathrm{M} / \mathrm{s} ; k_{\text {cat }} 0.70 \mathrm{~s}^{-1} ; k_{\text {cat }} / K_{m} 0.24$ $\left.\mathrm{s}^{-1} \mu \mathrm{M}^{-1}\right)$.

To compare the substrate specificities of the DFRs of maize and Petunia $\times$ hybrida, studies were also performed with recombinant Petunia $\times$ hybrida DFR $($ PhDFR). Purified recombinant, PhDFR showed no DHQ or DHK conversion and thus, a clear specificity for DHM (Table 2), which was also confirmed by the kinetic data $\left(K_{m} \quad 1.3 \mu \mathrm{M} ; \mathrm{V}_{\max } 0.5\right.$ $\left.\times 10^{-3} \mu \mathrm{M} / \mathrm{s} ; k_{\text {cat }} / K_{m} 2.14 \mathrm{~s}^{-1} ; k_{\text {cat }} / K_{m} 1.6 \mathrm{~s}^{-1} \mu \mathrm{M}^{-1}\right)$. Amino acid sequence identity between $P h D F R$ and $A_{1}$ is only $54 \%$. Particularly the region presumably determining substrate specificity shows a difference in positions 132-134 (amino acid numbering according PhDFR). To investigate whether the striking difference in the DHQ acceptance between the two recombinant DFRs is based on this region as suggested (Johnson et al., 2001), we created mutants with altered amino acids (Table 2). Whereas an exchange of the leucine with a valine in position 137 did not result in increased DHQ conversion, the exchange of aspartic acid with asparagine in position 138 raised DHQ conversion from zero to levels equaling those of DHM.

\section{Gene Expression in the Orange Petunia Varieties}

The transcriptomes of orange (cv. Salmon Ray), red (cv. Corso Rot) and black (cv. Blackberry) petunias were analyzed for differences in their gene expression pattern with respect to the phenotype. We particularly focused on the genes involved in color formation (Bombarely et al., 2016). The three varieties did not provide a uniform picture (Supplementary Figure S3). Whereas cv. Salmon Ray showed lower gene expressions in many of the structural genes of the flavonoid pathway, but not of the phenylpropanoid pathway, most of the structural genes in the early and late flavonoid pathway seemed to be up-regulated in the two other varieties. However, an increased DFR:FLS expression ratio was observed in the red and in all three orange cultivars compared to the black. This was further examined by quantitative real-time PCR.

Quantitative real-time PCR performed with primers discriminating between the DFRs from maize $\left(A_{1}\right)$ and petunia $(P h D F R)$ (Supplementary Table S1), showed that PhDFR expression strongly dominated over $A_{1}$ expression (Figure 2, bar charts) in developing buds of the orange varieties, despite being under the control of the strong, constitutive p35S promoter. $A_{1} / P h D F R$ expression ratios of approximately 1 could only be observed in open flowers. The qPCR studies also confirmed that the three orange petunia varieties had a low expression of F3' $H$ and FLS and thus a very high DFR:FLS expression ratio during the flower life cycle (Figure 6). There was, however, no statistically significant correlation between the $A_{1} / P h D F R$ expression ratios and the pelargonidin-type anthocyanidin concentration in the petals (Figure 2).

\section{DISCUSSION}

The DFR of petunia has ever been the role model for studies on DFR substrate specificity, and the resulting lack of orange flower color in petunia has always been the best example for the complex mechanisms of color establishment in flowers. The creation of an orange petunia by a transgenic approach in the 1980s at the Max Planck Institute for Plant Breeding Research in Cologne, Germany was a further landmark in the field of flower color research and the subsequent field trial attracted attention far beyond the horticultural community. Thus, the fact that petunia does not naturally possess orange flower color, and the underlying biochemical reason, has been established knowledge for a few decades (Meyer et al., 1986, 1992; Johnson et al., 1999, 2001). Therefore, the appearance of orange petunia varieties on the European market attracted the interest of scientists familiar with anthocyanin flower color. As they were not declared as genetically modified plants, which would have been compulsory if a transgenic breeding method had been used, they were apparently a result of classical breeding. Recent research demonstrated, however, that the vast majority of the commercially available orange petunia varieties, but not all, are genetically engineered and harbor the $A_{1}$ cDNA clone from Zea mays (Bashandy and Teeri, 2017). Despite the general consensus that the transgenic construct most probably derived from the first scientific GE-petunia (Meyer et al., 1986), it always remained unmentioned that there was a second scientific petunia (Elomaa et al., 1995), which was constructed with the same GE-elements, which could have been a possible source of the putatively unintentionally escaped $A_{1}$ cDNA clone. Our data unequivocally demonstrate, however, that of these two possible 
known sources, an unintentional release of the construct of the Elomaa et al. (1995) can indeed be excluded.

In an independent approach we analyzed three varieties released by breeders from three countries, The Netherlands, Israel and Germany. All three amplicons showed identical sequences (Supplementary Figure S1) at the nucleotide level (NCBI MF521566), demonstrating that a single $A_{1}$ source had entered breeding programmes worldwide. The sequence we obtained was in line with NCBI KY964325 (Bashandy and Teeri, 2017). There is, however, an overlap, as our primers started 699 bp downstream at the $5^{\prime}$-end, but provided an additional $375 \mathrm{bp}$ stretch at the $3^{\prime}$-end.

Our sequencing results identified with near absolute certainty the transformation construct of Meyer et al. (1986) as the $A_{1}$ source, based on the following characteristics (Figure 5, Supplementary Figure S1): the same arrangement of $35 \mathrm{~S}$ promoter, $A_{1}, 35 S$ terminator, nopaline synthase (NOS) promoter, nptII, octopine synthase (OCS) terminator, and the restriction sites used for the p35A1 plasmid construction, as described for the Meyer et al. (1986) construct, was identified (Figure 5). Pre-eminently, the transgene found in the three orange petunia varieties contains the $A_{1}$ type 2 allele previously used for plasmid p35A1 construction (Meyer et al., 1986), which includes, at the 3'end, an additional segment from the non-viral transposable Cin41 sequence (Schwarz-Sommer et al., 1987a). In addition, in the transition zone between the $35 S$ promoter and the $A_{1}$ gene, parts of the untranslated sequences of the $5^{\prime}$ flanking region, described previously (Schwarz-Sommer et al., 1987b), are present. This rules out other potential, as yet unidentified, sources, as it is unlikely that a putative third, yet unknown construct would harbor this special $A_{1}$ allele, particularly as the transposable element does not add any functional advantage with respect to color formation.

Unexpectedly, the orange petunias showed the same lack of DHK acceptance under common DFR assay conditions as the blue and red flowering non-GE controls. Concordantly, the orange petals accumulate large amounts of DHK derivatives (Table 1) that have not been ultimately converted to pelargonidin-based pigments. Such elevated dihydroflavonol levels were not found in common petunia varieties with a high $\mathrm{F}^{\prime} 5^{\prime} \mathrm{H}$ activity, as this favors creation of delphinidin based pigments. Likewise, in the absence of $\mathrm{F}^{\prime} 5^{\prime} \mathrm{H}$ activity, accumulated DHK and DHQ can be converted to flavonols, if FLS is active in the petals, as is the case in the red variety
(Table 1). The low substrate specificity for DHK was surprising, given the fact that $A_{1}$ had been introduced to explicitly enable conversion of DHK and thus, formation of pelargonidin based pigments. Much better color effects had been achieved by transformation with an unspecific gerbera DFR (Elomaa et al., 1995), thereby already pointing to a low substrate specificity of the maize DFR for DHK, although observed effects were rather attributed to the instability of monocotyledonous CDNA in the dicotyledonous petunia (Elomaa et al., 1995). The low substrate specificity of the protein encoded by the $A_{1}$ gene was confirmed with recombinant maize DFR obtained by heterologous expression in E. coli.

Only low expression rates were observed for the $A_{1}$ gene, which is in accordance with findings of epigenetic downregulation effects in GE-petunia (Linn et al., 1990; Meyer and Heidmann, 1994; Meyer, 1998). $A_{1}$ gene expression generally remained below the rates measured for the PhDFR. Highest expression was found in fully developed flowers, where an $A_{1} / P h D F R$ ratio of up to 1 could be measured. Despite this, the content of pelargonidin-based pigments remained surprisingly unchanged during flower development (Figure 2). There was, however, no statistically relevant correlation between the pelargonidin-based pigment concentration and the $A_{1}$ gene expression. Moreover, we never observed DHK conversion with enzyme preparations of the orange petunia petals independently of a high (open flowers) or low $A_{1} / P h D F R$ (buds) expression ratio, raising the question, if, besides the maize DFR, the petunia DFR could also contribute to pelargonidin-precursor production.

To determine how the orange coloration may occur at all, if a poorly expressed non-petunia $D F R$, with an additionally low substrate specificity for DHK, was present in GE-petunia petals, we compared the transcriptomes of the three orange varieties (cvs. Salmon Ray, Viva Orange, Electric Orange), red (cv. Corso Rot) and black (cv. Blackberry) petunias (Supplementary Figure S3) and analyzed the genes particularly involved in color formation (Bombarely et al., 2016). An increased DFR:FLS expression ratio in the red and orange cultivars was observed, compared to the black, which was confirmed by qPCR (Figure 6) and by the relatively small amounts of flavonols found in the petals of orange varieties (Table 1).

Apparently, the establishment of orange petunia flower color can occur only in the absence of interfering $\mathrm{F}^{\prime} \mathrm{H}$ and FLS activities (Figure 6). Considering the low substrate specificity of both $P h D F R$ and $A_{1}$ protein for DHK, sufficient

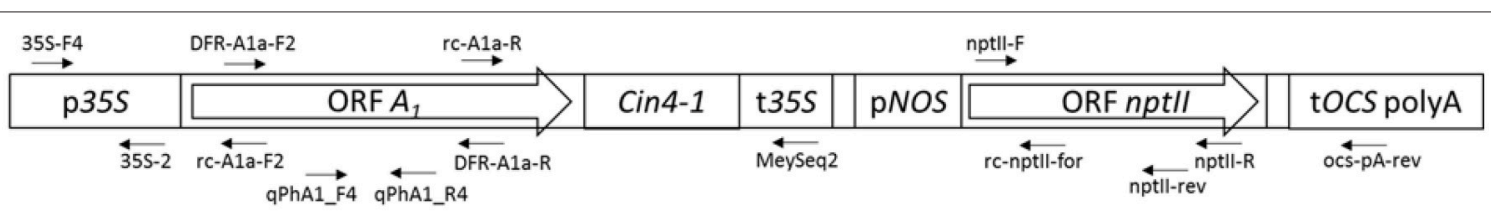

FIGURE 5 | Schematic representation of the transgenic insert found in the three GE-petunia varieties cvs. Salmon Ray, Viva Orange and Electric Orange (NCBI MF521566) p35S, promoter sequence of the 35S Cauliflower mosaic virus gene; $A_{1}$, coding sequence of the $A_{1}$ gene; Cin4-1, partial Cin4-1 transposable element present in type 2 allele of $A_{1}$ according to Schwarz-Sommer et al. (1987a,b); t35S, terminator sequence of the 35S Cauliflower mosaic virus gene; pNOS, promoter sequence of the nopaline synthase gene; nptll, coding sequence of the neomycine phosphotransferase II selectable marker gene; tOCS, terminator sequence of the octopine synthase gene. Positions of primers are marked by arrows. Primer sequences are provided in Supplementary Table S1. 

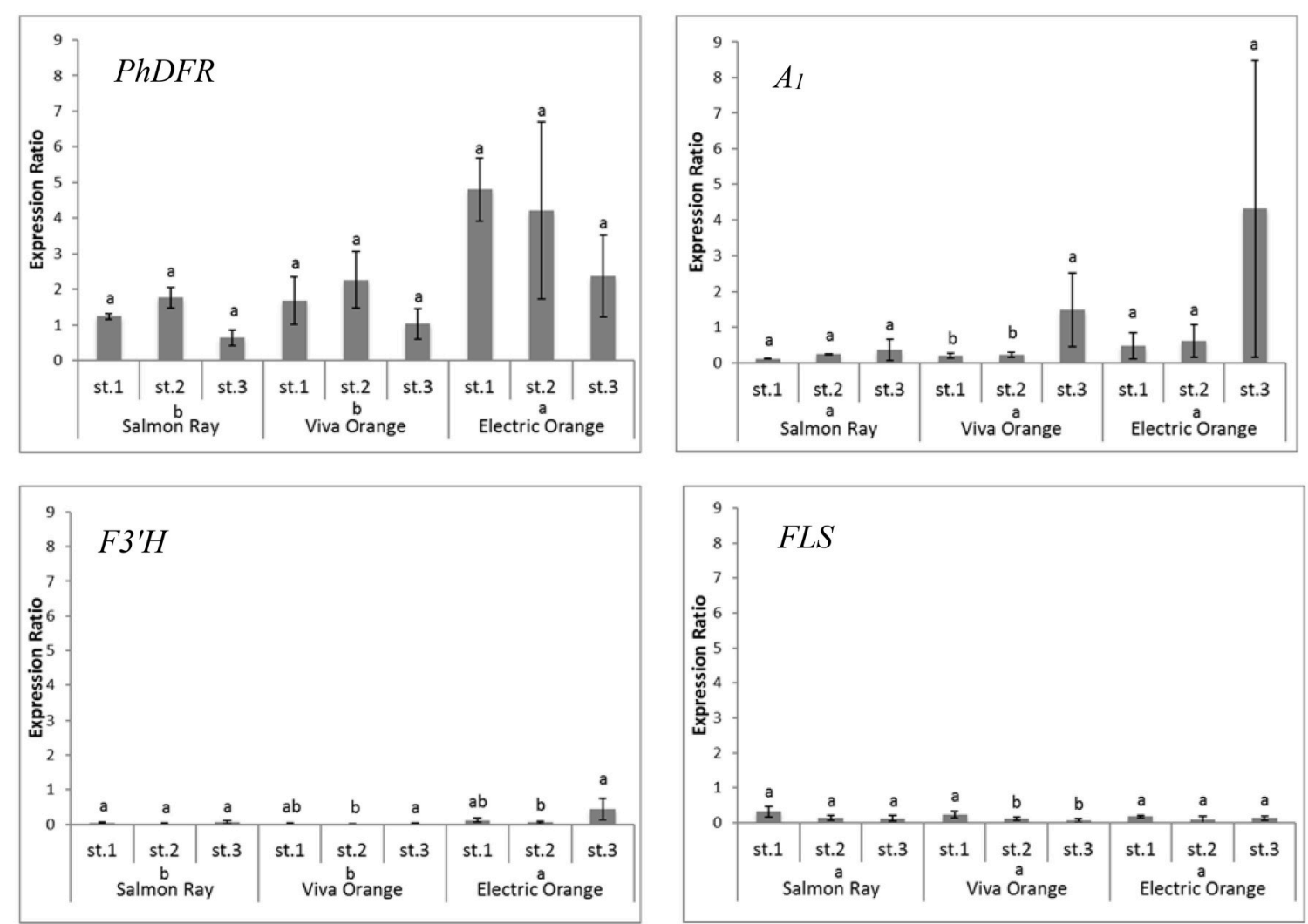

FIGURE 6 | Quantitative gene expression of PhDFR, $A_{1}, F 3^{\prime} H$ and $F L S$, normalized to actin in three developmental stages (st. 1: buds of $0.6-3 \mathrm{~cm}$ length, st. 2: buds of $3-5 \mathrm{~cm}$ length, st. 3: open flowers) of orange petunia flowers in three varieties (cvs. Salmon Ray, Viva Orange, Electric Orange). Average values were calculated from at least three biological replications collected at different sites. Error bars show standard deviation. Different letters above bars denote statistical difference according to Duncan test $(p<0.05)$ between the developmental stages separately for each variety. Different letters above cultivar names denote statistical difference according to Duncan test $(p<0.05)$ between the three varieties in general calculated from pooled stages.

leucopelargonidin precursor for pelargonidin-type flowers will be synthesized (i) very slowly over a long time, (ii) only if no other dihydroflavonol precursor is present (absent or low $\mathrm{F}^{\prime} \mathrm{H}$ and $\mathrm{F}^{\prime} 5^{\prime} \mathrm{H}$ activity), and (iii) if the accumulating DHK is not redirected by a highly active FLS toward flavonols. In the same way, cyanidin-based red flowering petunia varieties occur naturally, despite the fact that PhDFR shows stringent specificity for DHM as substrate (Table 2). The red cultivar used as a control accumulates a substantial amount of dihydroflavonols, however, thereby confirming the low FLS expression and elevated DFR:FLS expression ratio in the red cultivars already indicated by the transcriptome analysis. Considering the DFR substrate specificity of petunia for DHM, increased flavonol formation, at the expense of anthocyanin accumulation, and thus, only a pale color, would be expected in the case of a highly active petunia FLS. The elaborate creation of transgenic petunia and the current global commotion surrounding the escaped $A_{1}$ gene seem to be a great cause, in comparison to the relatively small color effects attained by the use of the inefficient maize DFR.

American and European authorities unambiguously stated that the GE-petunia is not harmful to consumers and environment. It is still unknown, how plants harboring the $A_{1}$ construct of Meyer et al. (1986) entered classical breeding programmes. Nefarious use of GE-plants is unlikely, due to foreseeable troubles when plants inevitably attract attention. There are, however, several scenarios how the GE-petunia could have escaped. After its creation at the Max Planck Institute for Plant Breeding Research in Cologne (Meyer et al., 1986), and the contentious field trial in Germany in 1990, the plants were kept in several institutions, and were also used for breeding purposes (Oud et al., 1995; Servick, 2017), followed by field trials in the US. Currently, the most favored explanation (Servick, 2017) seems to be that during a chain of company fusions the GE-background of orange petunias was forgotten, and the lines could therefore enter new breeding programmes. Our results demonstrate why the presence of the $A_{1}$ does not result in orange phenotypes in a common biochemical petunia background, which facilitates undetected dispersion. Thus, the original GE-petunia (Meyer et al., 1986) or progenies thereof, created by classical breeding (Oud et al., 1995) or-less likely_by escaped pollen, in the field or in the greenhouse, could have infiltrated classical breeding chains, unless it re-emerged as orange petunia in a rare event of a proper genetic background. The large spectrum of undeclared GE-petunia varieties can be explained by the use of early orange varieties as parent plants in classical breeding attempts for further orange varieties by other companies and by the use of non-orange 
breeding material harboring an unrecognized $A_{1}$. The fact that a single construct was found so far in the orange petunia varieties, as opposed to plural different constructs, points at a single event in the breeding chain rather than at multiple parallel events.

In the current debate, it was iterated that real orange petunia flower colors cannot occur naturally (David, 2017). Some few petunia varieties, however, show a pattern of red and yellow pigments that, at a glance, might be mistaken for orange (Bashandy and Teeri, 2017). But even minor mutations in the active site of the DFR can result in higher DHK specificity, as demonstrated by the existing patent for a DHK specific DFR (Johnson et al., 2001). A spontaneous mutation occurring in a suitable background, although unlikely, could indeed provide a naturally orange-flowering petunia. This could also be achieved by cutting-edge genome editing methods causing a targeted mutation, which can currently not be distinguished from mutations induced by well accepted methods such as mutation via chemicals or radiation. It remains to be seen how the escaped GE-petunias will influence the current debate about the classification of genome editing as a genetic engineering method, and on biotech patents in general, which was provoked by the recent barley patents obtained by large brewing companies.

\section{AVAILABILITY OF DATA AND MATERIALS}

All data supporting the findings is contained in the manuscript and its supplementary files. Transcriptome data are available

\section{REFERENCES}

Bashandy, H., and Teeri, T. H. (2017). Genetically engineered orange petunias on the market. Planta 246, 277-280. doi: 10.1007/s00425-017-2722-8

Bolger, A. M., Lohse, M., and Usadel, B. (2014). Trimmomatic: a flexible trimmer for Illumina sequence data. Bioinformatics 30, 2114-2120. doi: 10.1093/bioinformatics/btu170

Bombarely, A., Moser, M., Amrad, A., Bao, M., Bapaume, L., Barry, C. S., et al. (2016). Insight into the evolution of the Solanaceae from the parental genomes of Petunia hybrida. Nat. Plants 2:16074. doi: 10.1038/nplants.2016.74

David, M. (2017). U.S. flower sellers rush to destroy illegal GE petunias. Sci. Post. Plants Anim. Sci. Policy. doi: 10.1126/science.aal1200

De Mendiburu, F. (2017). Agricolae: Statistical Procedures for Agricultural Research. $\mathrm{R}$ package version 1.2-8. Available online at: https://CRAN.R-project.org/ package $=$ agricolae.

Duncan, D. B. (1955). Multiple range and multiple F tests. Biometrics 11, 1-42. doi: $10.2307 / 3001478$

Elomaa, P., Helariutta, Y., Kotilainen, M., Teeri, T. H., Griesbach, R. J., and Seppänen, P. (1995). Transgene inactivation in Petunia hybrida is influenced by the properties of the foreign gene. Mol. Gen. Genet. 248, 649-656. doi: 10.1007/BF02191704

Gosch, C., Nagesh, K. M., Thill, J., Miosic, S., Plaschil, S., Milosevic, M., et al. (2014). Isolation of Dihydroflavonol 4-Reductase cDNA Clones from Angelonia $\times$ angustifolia and Heterologous Expression as GST Fusion Protein in Escherichia coli. PLoS ONE 9:e107755. doi: 10.1371/journal.pone.0107755

Halbwirth, H. (2010). The creation and physiological relevance of divergent hydroxylation patterns in the flavonoid pathway. Int. J. Mol. Sci. 11, 595-621. doi: 10.3390/ijms11020595

Halbwirth, H., Kahl, S., Jager, W., Reznicek, G., Forkmann, G., and Stich, K. (2006). Synthesis of $\left({ }^{14} \mathrm{C}\right)$-labeled 5-deoxyflavonoids and their application in the study of dihydroflavonol/leucoanthocyanidin interconversion by dihydroflavonol 4reductase. Plant Sci. 170, 587-595. doi: 10.1016/j.plantsci.2005.10.013 at the Short Read Archive of the International Nucleotide Sequence Database Collaboration: SAMN07988829 (Petunia $\times$ hybrida cv. Blackberry), SAMN07988830 (Petunia $\times$ hybrida cv. Corso Rot), SAMN07988831 (Petunia $\times$ hybrida cv. Viva Orange), SAMN07988832 (Petunia $\times$ hybrida cv. Electric Orange), SAMN07988833 (Petunia $\times$ hybrida cv. Salmon Ray).

\section{AUTHOR CONTRIBUTIONS}

$\mathrm{HH}, \mathrm{CH}-\mathrm{G}$, and KS: Conceived the research and wrote the manuscript; SM, DN, BR, BW, RP, RL, and LE: conducted the experiments; TR and KO: analyzed the data. All authors approved the manuscript.

\section{FUNDING}

We acknowledge funding by the Austrian Science Fund (FWF) P 28134-B25 and from the European Union's Horizon 2020 research and innovation program under the Marie SkłodowskaCurie grant agreement No 675657.

\section{SUPPLEMENTARY MATERIAL}

The Supplementary Material for this article can be found online at: https://www.frontiersin.org/articles/10.3389/fpls.2018. 00149/full\#supplementary-material
Ihaka, R., and Gentleman, R. (1996). R: a language for data analysis and graphics. J. Comput. Graph. Stat. 5, 299-314.

Johnson, E. T., Ryu, S., Yi, H., Shin, B., Cheong, H., and Choi, G. (2001). Alteration of a single amino acid changes the substrate specificity of dihydroflavonol 4-reductase. Plant J. 25, 325-333. doi: 10.1046/j.1365-313x.2001.00962.x

Johnson, E. T., Yi, H., Shin, B., Oh, B. J., Cheong, H., and Choi, G. (1999). Cymbidium hybrida dihydroflavonol 4-reductase does not efficiently reduce dihydrokaempferol to produce orange pelargonidin-type anthocyanins. Plant J. 19, 81-85. doi: 10.1046/j.1365-313X.1999.00502.x

Kopylova, E., Noé, L., and Touzet, H. (2012). SortMeRNA: fast and accurate filtering of ribosomal RNAs in metatranscriptomic data. Bioinformatics 28, 3211-3217. doi: 10.1093/bioinformatics/bts611

Li, B., and Dewey, C. N. (2011). RSEM: accurate transcript quantification from RNA-Seq data with or without a reference genome. BMC Bioinformatics 12:323. doi: 10.1186/1471-2105-12-323

Linn, F., Heidmann, I., Saedler, H., and Meyer, P. (1990). Epigenetic changes in the expression of the maize Al gene in Petunia hybrida: role of numbers of integrated gene copies and state of methylation. Mol. Gen. Genet. 222, 329-336. doi: $10.1007 / \mathrm{BF} 00633837$

Lipp, M., Brodmann, P., Pietsch, K., Pauwels, J., Anklam, E., Borchers, T., et al. (1999). IUPAC collaborative trial study of a method to detect genetically modified soy beans and maize in dried powder. J. AOAC Int. 82, 923-928.

Mallona, I., Lischewski, S., Weiss, J., Hause, B., and Egea-Cortines, M. (2010). Validation of reference genes for quantitative real-time PCR during leaf and flower development in Petunia hybrida. BMC Plant Biol. 10:4. doi: 10.1186/1471-2229-10-4

Meyer, P. (1998). Stabilities and instabilities in transgene expression. Trans. Plant Res. 263-275.

Meyer, P., and Heidmann, I. (1994). Epigenetic variants of a transgenic petunia line show hypermethylation in transgene DNA: an indication for specific recognition of foreign DNA in transgenic plants. Mol. Gen. Genet. 243, 390-399. 
Meyer, P., Heidmann, I., Forkmann, G., and Saedler, H. (1986). A new petunia flower colour generated by transformation of a mutant with a maize gene. Nature 330, 677-678. doi: 10.1038/330677a0

Meyer, P., Linn, F., Heidmann, I., Meyer, H., Niedenhof, I., and Saedler, H. (1992). Endogenous and environmental factors influence $35 \mathrm{~S}$ promoter methylation of a maize A1 gene construct in transgenic petunia and its colour phenotype. Mol. Gen. Genet. 231, 345-352. doi: 10.1007/BF00292701

Miosic, S., Thill, J., Milosevic, M., Gosch, C., Pober, S., Molitor, C., et al. (2014). Dihydroflavonol 4-reductase genes encode enzymes with contrasting substrate specificity and show divergent gene expression profiles in Fragaria Species. PLoS ONE 9:e112707. doi: 10.1371/journal.pone.0112707

Oud, J. S., Schneiders, H., Kool, A. J., and Van Grinsven, M. Q. (1995). Breeding of transgenic orange Petunia hybrida varieties. Euphytica 84, 175-181. doi: $10.1007 /$ BF01681809

Petit, P., Granier, T., d'estaintot, B. L., Manigand, C., Bathany, K., Schmitter, J. M., et al. (2007). Crystal structure of grape Dihydroflavonol 4-Reductase, a Key Enzyme in Flavonoid Biosynthesis+. J. Mol. Biol. 368, 1345-1357. doi: 10.1016/j.jmb.2007.02.088

Pfaffl, M. W. (2001). A new mathematical model for relative quantification in real-time RT-PCR. Nucleic Acids Res. 29:e45. doi: 10.1093/nar/29.9.e45

Razali, N. M., and Wah, Y. B. (2011). Power comparisons of shapiro-wilk, kolmogorov-smirnov, lilliefors and Anderson-darling tests. J. Stat. Model. Anal. 2, 21-33.

Schwarz-Sommer, Z., Leclercq, L., Göbel, E., and Saedler, H. (1987a). Cin4, an insert altering the structure of the A1 gene in Zea mays, exhibits properties of nonviral retrotransposons. EMBO J. 6:3873.

Schwarz-Sommer, Z., Shepherd, N., Tacke, E., Gierl, A., Rohde, W., Leclercq, L., et al. (1987b). Influence of transposable elements on the structure and function of the A1 gene of Zea mays. EMBO J. 6:287.
Servick, K. (2017). The strange case of the orange petunias. Science 356:792. doi: $10.1126 /$ science.356.6340.792

Tanaka, Y., Brugliera, F., and Chandler, S. (2009). Recent progress of flower colour modification by biotechnology. Int. J. Mol. Sci. 10, 5350-5369. doi: 10.3390/ijms10125350

Tanaka, Y., Brugliera, F., Kalc, G., Senior, M., Dyson, B., Nakamura, N., et al. (2010). Flower color modification by engineering of the flavonoid biosynthetic pathway: practical perspectives. Biosci. Biotechnol. Biochem. 74, 1760-1769. doi: 10.1271/bbb.100358

Thill, J., Miosic, S., Ahmed, R., Schlangen, K., Muster, G., Stich, K., et al. (2012). 'Le Rouge et le Noir': a decline in flavone formation correlates with the rare color of black dahlia (Dahlia variabilis hort.) flowers. BMC Plant Biol. 12:225. doi: 10.1186/1471-2229-12-225

Winkel-Shirley, B. (2001). Flavonoid biosynthesis. a colorful model for genetics, biochemistry, cell biology, and biotechnology. Plant Physiol. 126:485. doi: $10.1104 /$ pp.126.2.485

Conflict of Interest Statement: The authors declare that the research was conducted in the absence of any commercial or financial relationships that could be construed as a potential conflict of interest.

Copyright (c) 2018 Haselmair-Gosch, Miosic, Nitarska, Roth, Walliser, Paltram, Lucaciu, Eidenberger, Rattei, Olbricht, Stich and Halbwirth. This is an open-access article distributed under the terms of the Creative Commons Attribution License (CC $B Y)$. The use, distribution or reproduction in other forums is permitted, provided the original author(s) and the copyright owner are credited and that the original publication in this journal is cited, in accordance with accepted academic practice. No use, distribution or reproduction is permitted which does not comply with these terms. 